\title{
Dissociable contributions of MRI volume reductions of superior temporal and fusiform gyri to symptoms and neuropsychology in schizophrenia
}

\section{Citation}

Nestor, Paul G., Toshiaki Onitsuka, Ronald J. Gurrera, Margaret Niznikiewicz, Melissa Frumin, Martha E. Shenton, and Robert W. McCarley. 2007. “Dissociable Contributions of MRI Volume Reductions of Superior Temporal and Fusiform Gyri to Symptoms and Neuropsychology in Schizophrenia." Schizophrenia Research 91 (1-3) (March): 103-106. doi:10.1016/j.schres.2006.11.025.

\section{Published Version}

doi:10.1016/j.schres.2006.11.025

\section{Permanent link}

http://nrs.harvard.edu/urn-3:HUL.InstRepos:28552570

\section{Terms of Use}

This article was downloaded from Harvard University's DASH repository, and is made available under the terms and conditions applicable to Other Posted Material, as set forth at http:// nrs.harvard.edu/urn-3:HUL.InstRepos:dash.current.terms-of-use\#LAA

\section{Share Your Story}

The Harvard community has made this article openly available. Please share how this access benefits you. Submit a story. 


\title{
Dissociable contributions of MRI volume reductions of superior temporal and fusiform gyri to symptoms and neuropsychology in schizophrenia *
}

\author{
Paul G. Nestor ${ }^{a}, c^{,}{ }^{*}$, Toshiaki Onitsukab,c, Ronald J. Gurrerac, Margaret Niznikiewicz ${ }^{\mathrm{C}}$, \\ Melissa Frumin ${ }^{b, c}$, Martha E. Shenton ${ }^{b, c}$, and Robert W. McCarley ${ }^{c}$ \\ aDepartment of Psychology, University of Massachusetts, Boston, United States \\ bSurgical Planning Laboratory, MRI Division, Department of Radiology, Brigham and Women's \\ Hospital, Harvard Medical School, Boston, MA, United States \\ ${ }^{\circ}$ Clinical Neuroscience Division, Laboratory of Neuroscience, Boston VA Health Care System- \\ Brockton Division, Department of Psychiatry, Harvard Medical School, Boston, MA, United States
}

\begin{abstract}
We sought to identify the functional correlates of reduced magnetic resonance imaging (MRI) volumes of the superior temporal gyrus (STG) and the fusiform gyrus (FG) in patients with chronic schizophrenia. MRI volumes, positive/negative symptoms, and neuropsychological tests of facial memory and executive functioning were examined within the same subjects. The results indicated two distinct, dissociable brain structure-function relationships: (1) reduced left STG volume-positive symptoms-executive deficits; (2) reduced left FG-negative symptoms-facial memory deficits. STG and FG volume reductions may each make distinct contributions to symptoms and cognitive deficits of schizophrenia.
\end{abstract}

\section{Keywords}

Schizophrenia; MRI; Neuropsychology; Symptoms

\section{Introduction}

The superior temporal gyrus (STG) and the fusiform gyrus (FG) are two functionally distinct regions, which are among the several brain areas that have been identified as showing reduced volumes in magnetic resonance imaging (MRI) studies of patients with schizophrenia (Onitsuka et al., 2003, 2004, 2005). Each of these areas may be linked to different facets of the well-known heterogeneous expression of schizophrenia. For example, reduced left STG volume has been linked to positive symptoms of auditory hallucinations (Barta et al., 1990; Gaser et al., 2004) and thought disorder (Shenton et al., 1992; McCarley et al., 1993) as well as to neuropsychological executive deficits (Nestor et al., 1993). In contrast, reduced left FG volume has been associated with both poor facial recognition (Onitsuka et al., 2003) and

\footnotetext{
诂This work was supported by the National Institute of Health (K02 MH 01110 and R01 MH 50747 to MES, R01 MH 40799 to RWM, RO1 MH 63360 to MN), the Department of Veterans Affairs Merit Awards (MES, MN, PGN, RWM), the Department of Veterans Affairs REAP Award (RWM), the MIND Institute (Albuquerque, NM) and a VA Psychiatry/Neuroscience Research Fellowship Award (MF). (C) 2006 Elsevier B.V. All rights reserved.

*Corresponding author. Department of Psychology, University of Massachusetts-Boston, Boston, MA 02125-3393, United States. Tel.: +1 617287 6387. paul.nestor@umb.edu (P.G. Nestor).
} 
introversion, consistentwith negative symptom descriptors of social withdrawal (Onitsuka et al., 2005). Whether these structural-functional relationships can be dissociated within the same subjects is, however, unknown, as these prior studies have mainly examined behavioral correlates of STG and FG across different patient samples.

The current study thus aimed to extend these previous findings by examining and comparing within the same subjects functional correlates of reduced STG and FG volumes. Based on previous studies, we predicted STG and FG would each make distinct and specific contributions to different aspects of the phenotype of schizophrenia, as expressed in symptoms and neuropsychological test performance. To wit, reduced left STG volume is hypothesized to correlate with both positive symptoms and neuropsychological executive deficits, but not with negative symptoms and facial memory deficits, which are both hypothesized to correlate only with reduced left FG.

\section{Method}

\subsection{Participants}

Subjects were 22 medicated male patients, who had prior high-spatial resolution MRI gray matter studies of the STG (Onitsuka et al., 2003) and the FG (Onitsuka et al., 2004, 2005), and who were between the ages of 17 and 55 years (Mean=41.43 years, $\mathrm{SD}=8.22$ ), righthanded, native speakers of English, without histories of electroconvulsive therapy or neurological illness, and without alcohol or drug abuse in the past 5 years, as assessed by the Addiction Severity Index (McLellan et al., 1992). Recruited from the VA Boston Healthcare System, Brockton Campus, patients were diagnosed with schizophrenia using the Structured Clinical Interview for DSM-IVAxis-I Disorder-Patient Edition (SCID-P) (First et al., 1997). Mean chlorpromazine equivalent daily dose was $576 \mathrm{mg}(\mathrm{SD}=257)$ (Stoll unpublished, 2003), with 12 patients taking atypical medication, 9 typical medication, and one received both. The mean duration of illness was 20.7 years $(\mathrm{SD}=8.5)$.

\subsection{Measures}

The Positive and Negative Syndrome Scale (PANSS) provides objective ratings of various positive and negative symptoms (Kay et al., 1986). The neuropsychological tests included measures of executive functioning, the Wisconsin Card Sorting Test (WCST), and delayed facial recognition, as assessed by the Faces II subtest of the Wechsler Memory Scale (WMSIII).

The MRI protocol, described in detail in other published studies (Onitsuka et al., 2003, 2004), acquired MR images with a 1.5-T General Electric scanner (GE Medical Systems, Milwaukee) at the Brigham and Women's Hospital in Boston (see Fig. 1). Manual drawings of the FG were performed on the coronal plane, blind to diagnoses (control data were not examined in this study). The anterior landmark was reliably defined by one slice posterior to the mamillary body, and the posterior landmark was determined by the anterior tip of the parietal-occipital sulcus in the midsagittal plane. The last slice including the crux of the fornix provided the boundary for subdivision of FG into anterior and posterior. The collateral sulcus was used as the medial border. The occipital-temporal sulcus was used to determine the lateral border. Inter-rater reliability was computed for the FG by 3 independent raters who were blind to group membership. The intra-class correlations were: 0.94 for left anterior FG, 0.94 for the right anterior, 0.95 for the left posterior, 0.95 for the right posterior. For the STG, the anterior boundary was defined as the first slice containing the intact temporal stem. The posterior landmark was determined by the last slice including the crux of the fornix. Superior temporal sulcus was used as the inferior border. Inter-rater reliability was computed for the STG by 3 
independent raters, blind to group membership. The intra-class correlations for inter-rater reliability were: 0.97 for left STG, 0.98 for right STG.

\section{Results}

Table 1 presents symptom and neuropsychological correlates of STG and FG volumes. As shown in Table 1, reduced left FG volume correlated significantly with higher negative symptoms (rho=- $.439, p<.05$ ) but not with positive symptoms. In contrast, reduced left STG volume correlated significantly with higher positive symptoms $(\mathrm{rho}=-.494, p<.05)$ but not with negative symptoms. The strongest correlations among the specific symptom items were for the negative symptom emotional withdrawal and left FG volume ( $\mathrm{rho}=-.467, p<.05)$, and for the positive symptom hallucinations and left STG (rho $=-.613, p<.01)$. For the neuropsychological scores, reduced left FG also correlated significantly with lower scores for facial memory (rho=. $609, p=.01$ ), whereas reduced left STG volume correlated significantly with increased nonperseverative WCST errors, a measure of executive functioning (rho $=-.479, p<.05)$. Neither positive symptoms nor negative symptoms correlated significantly with neuropsychological scores for facial memory or executive functioning.

We next used hierarchical multiple regression to compare, quantify, and parse these significant functional correlates of the FG and the STG. For negative symptoms, reduced left FG volume emerged as the sole contributor, accounting for $23 \%$ of the variance in negative symptoms, $(F=5.75, d f=1,20, p<.05)$; posterior and anterior segments of the left FG did not account for any significant variation in negative symptoms. By comparison, reduced left STG volume accounted for $19 \%$ of the variance in positive symptoms $(F=4.63, d f=1,20, p<.05)$, with reductions of the left posterior STG volume making an even greater contribution, accounting for $25 \%$ of the variance in positive symptoms $(F=6.48, d f=1,20, p<.05)$. For neuropsychological correlates, reductions of the left anterior FG contributed significantly to lower facial memory scores, accounting for $33 \%$ of the variance $(F=6.80, d f=1,14, p<.05)$. Similarly, left posterior STG volume accounted for $22 \%$ of the variance in errors in executive functioning, $(F=5.27, d f=1,19, p<.05)$.

\section{Discussion}

We compared within the same subjects with schizophrenia functional correlates of reductions in the STG and the FG. The results suggested that the STG and the FG may each account for different facets of the schizophrenic phenotype, as expressed in symptoms and neuropsychological test performance. That is, as predicted, the results pointed to two distinct, dissociable brain structure-function relationships: (1) reduced left STG volume-positive symptoms-executive deficits; (2) reduced left FG-negative symptoms-facial memory deficits. Seldom have patterns of correlations provided such clear evidence as in the current study of a double dissociation of anatomy and function in schizophrenia as reflected by the nonoverlapping reduced left STG volume with positive symptoms and executive deficits versus reduced left FG volume with negative symptoms and facial memory deficits.

The current study integrated neuroimaging, neuropsychology, and symptom ratings so as to parse the different facets of the well-known heterogeneous phenotype of schizophrenia, and to understand better its social and cognitive consequences. As such, the current findings may add to the future social-cognitive neuroscience study of schizophrenia. However, schizophrenia affects diverse areas of the brain, and future studies are needed that use a broader sampling of brain regions in unselected group of patients, preferably unmedicated, with a wider range of length of illness than those of the present investigation. 


\section{References}

Barta PE, Pearlson GD, Powers RE, Richards SS, Lune LE. Auditory hallucinations and smaller superior temporal gyral volume in schizophrenia. Am. J. Psychiatry 1990;147:1457-1462. [PubMed: 2221156]

First, MB.; Spitzer, RL.; Gibbon, M.; Williams, JBW. Structured Clinical Interview for DSM-IV Axis I Disorders - Clinician Version. American Psychiatric Press; Washington, DC: 1997.

Gaser C, Nenadic I, Volz HP, Buchel C, Sauer H. Neuroanatomy of 'hearing voices': a frontotemporal brain structural abnormality associated with auditory hallucinations in schizophrenia. Cereb. Cortex 2004;14:91-96. [PubMed: 14654460]

Kay, SR.; Opler, LA.; Fiszbein, A. Positive and Negative Syndrome Scale (PANSS). Multi-Health Systems, Inc.; New York, NY: 1986.

McCarley RW, Shenton ME, O’Donnell BF, Faux SF, Kikinis R, Nestor PG, Jolesz FA. Auditory P300 abnormalities and left posterior superior temporal gyrus volume reduction in schizophrenia. Arch. Gen. Psychiatry 1993;50:190-197. [PubMed: 8439239]

McLellan AT, Kushner H, Metzger D, Peters R, Smith I, Grissom G, Pettinati H, Argeriou M. The fifth edition of the addiction severity index. J. Subst. Abuse Treat 1992;9:199-213. [PubMed: 1334156]

Nestor PG, Shenton ME, McCarley RW, Haimson J, Smith RS, O’Donnell B, Kimble M, Kikinis R, Jolesz FA. Neuropsychological correlates of MRI temporal lobe abnormalities in schizophrenia. Am. J. Psychiatry 1993;150:1849-1855. [PubMed: 8238641]

Onitsuka T, Shenton ME, Kasai K, Nestor PG, Toner SK, Kikinis R, Jolesz FA, McCarley RW. Fusiform gyrus volume reduction and facial recognition in chronic schizophrenia. Arch. Gen. Psychiatry 2003;60:349-355. [PubMed: 12695311]

Onitsuka T, Shenton ME, Salisbury DF, Dickey CC, Kasai K, Toner SK, Frumin M, Kikinis R, Jolesz FA, McCarley RW. Middle and inferior temporal gyrus gray matter volume abnormalities in schizophrenia: an MRI study. Am. J. Psychiatry 2004;161:1603-1611. [PubMed: 15337650]

Onitsuka T, Nestor PG, Gurrera RJ, Shenton ME, Kasai K, Frumin M, Niznikiewicz M, McCarley RW. Association between reduced extraversion and right posterior fusiform gyrus gray matter reduction in chronic schizophrenia. Am. J. Psychiatry 2005;162:599-601. [PubMed: 15741479]

Shenton ME, Kikinis R, Jolesz FA, Pollak SD, LeMay M, Wible CG, Hokama H, Martin J, Metcalf D, Coleman M. Abnormalities of the left temporal lobe and thought disorder in schizophrenia: a quantitative MRI study. N. Engl. J. Med 1992;327:604-612. [PubMed: 1640954] 

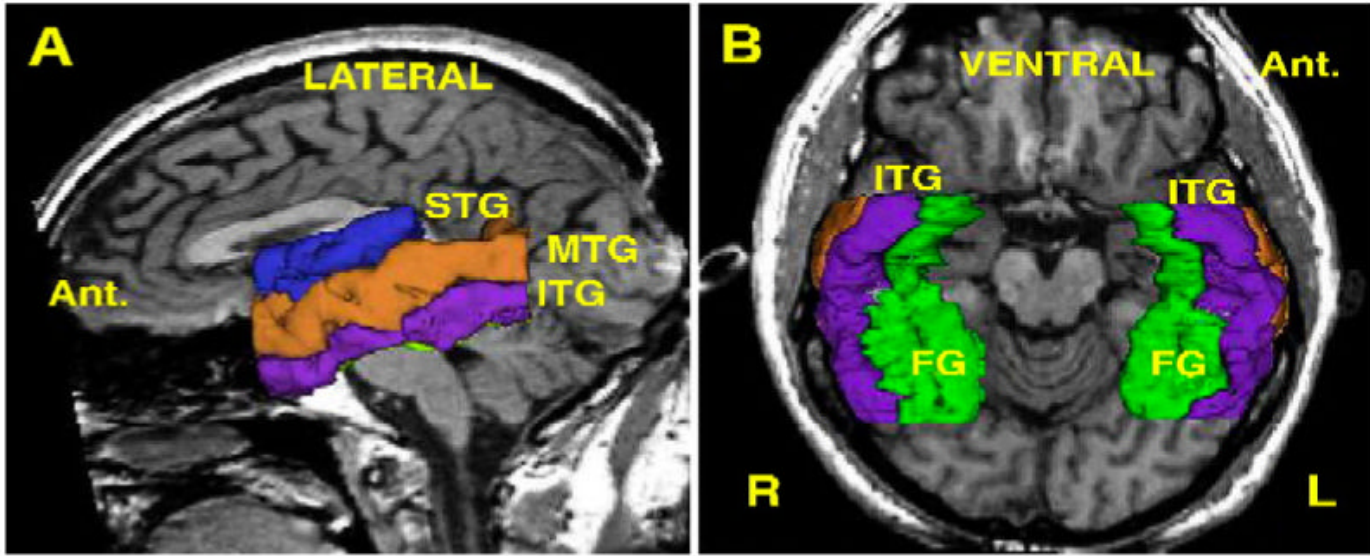

Fig. 1.

Superior temporal gyrus (blue), middle temporal gyrus (tan), inferior temporal gyrus (purple), and fusiform gyrus (green) from lateral (a) and ventral (B) views. 
Table 1

Spearman Rank correlations of MRI volumes with symptom ratings and neuropsychological scores

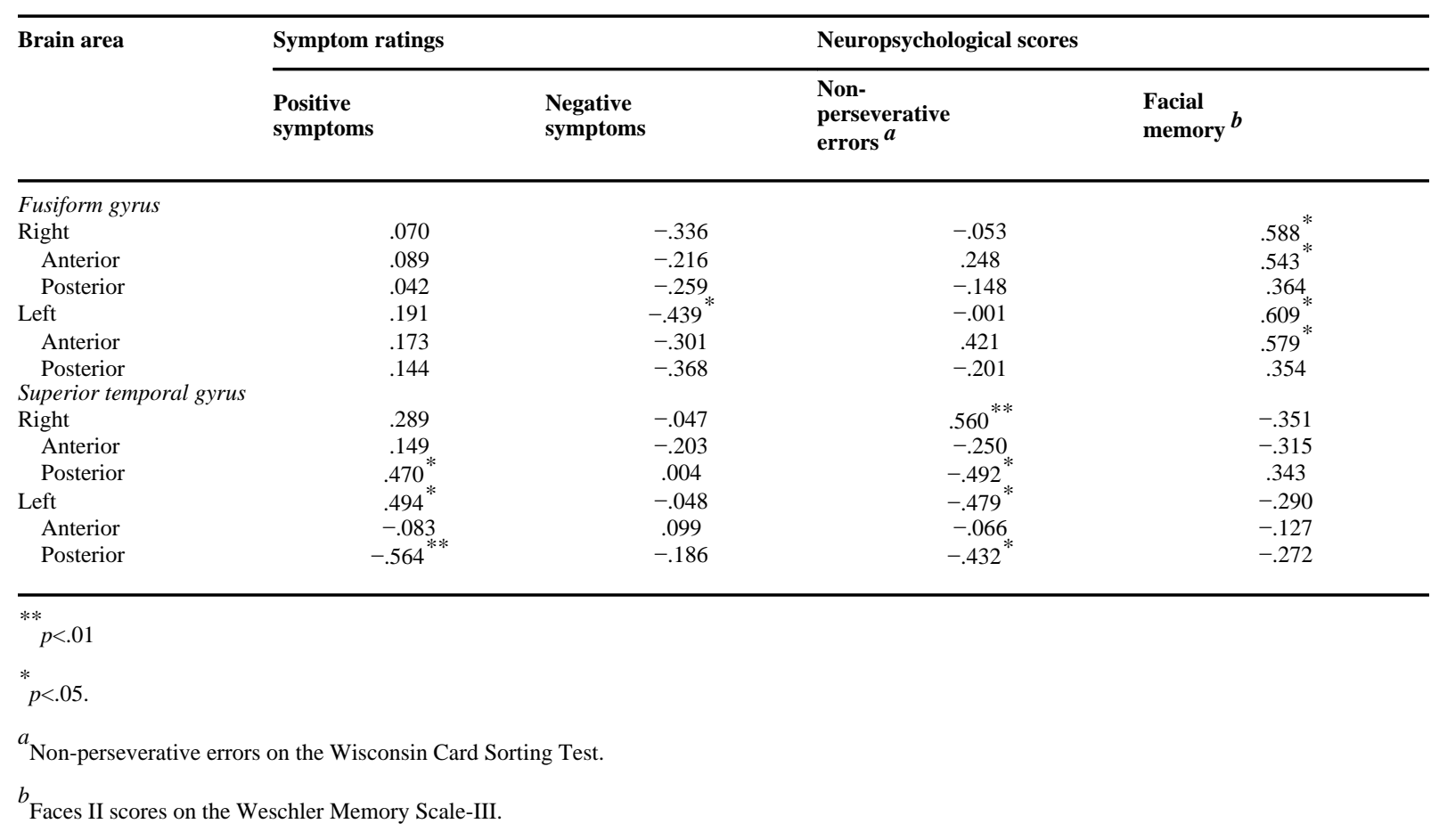

